\title{
Towards the Significance of Decision Aid in Building Information Modeling (BIM) Software Selection Process
}

\author{
Mohd Faizal Omar ${ }^{1}$, Mohd Nasrun Mohd Nawi ${ }^{2}$, Ahmad Taufik Nursal ${ }^{3}$ \\ ${ }^{1,3}$ Department of Decision Science, College of Arts and Sciences, Universiti Utara Malaysia, 06010 \\ Sintok, Kedah Malaysia \\ ${ }^{2}$ Department of Technology \& Operation Management, School of Technology Management \& \\ Logistics, Universiti Utara Malaysia, 06010 Sintok, Kedah Malaysia
}

\begin{abstract}
Building Information Modeling (BIM) has been considered as a solution in construction industry to numerous problems such as delays, increased lead in times and increased costs. This is due to the concept and characteristic of BIM that will reshaped the way construction project teams work together to increase productivity and improve the final project outcomes (cost, time, quality, safety, functionality, maintainability, etc.). As a result, the construction industry has witnesses numerous of BIM software available in market. Each of this software has offers different function, features. Furthermore, the adoption of BIM required high investment on software, hardware and also training expenses. Thus, there is indentified that there is a need of decision aid for appropriated BIM software selection that fulfill the project needs. However, research indicates that there is limited study attempt to guide decision in BIM software selection problem. Thus, this paper highlight the importance of decision making and support for BIM software selection as it is vital to increase productivity, construction project throughout building lifecycle.
\end{abstract}

\section{Introduction}

The current Architechture, Engineering and Construction (AEC) industry building process has been fragmented and the paper based communication is considered to be the drawback [1]. Errors, changes, omissions result in upgrading the design a number of times sequentially by different parties [2]. In addition to this, the various interpretations of a single design intent by different parties lead to even more complexities. With the introduction of ICT technologies like 2D CAD, the time spent on redrafting a change in the design has been reduced [1]. However, the practice of sequential design changes, omissions, errors, different interpretations remain the same [2]. As well, while incorporating the changes and confirming that every consultant is on the same page with respect to design intent; the major aspect of achieving the project goals becomes secondary. Collaboration and communication among the parties involved in construction project is the key for the project successful[3].However, $2 \mathrm{D}$ CAD is based on fragmented process which is happen due to the lack of collaboration and communication the stakeholders. During the last decade, the major shift in ICT for the AEC industry has been the proliferation of Building Information Modeling (BIM) in industrial and academic circles.

BIM is the most commonly used term to describe a set of parametric tools and processes for the creation and maintenance of an integrated collaborative database of multi-dimensional 
information regarding the design, construction and/or operations of a building, with the purpose of improving collaboration between stakeholders, reducing the time needed for documentation of the project and producing more predictable project outcomes.

Nowadays, various BIM software package available in the market that provide a different capabilities and function according to constructor needs such as Revit, Bentley, Archicad 12, Innovaya, Synchro, Vico, Tekla, Onuma, Solibri, etc.[4]. Each of these software packages has their own specialization in term of function and implementation. It is vital to select appropriate BIM software due to variability of cost and features as it can affect the overall construction project execution throughout building lifecycle. In contrast, investigation into selection criteria and decision process to select appropriate BIM software are until recently, relatively limited. Most of the company tend to follow market trend, software package that they are familiar, and choose software that is more popular in industry without having a proper analysis for a value decision making[5]. Considering the current situation in the industry, this paper discusses the importance of decision making for BIM software selection in construction industry.

\section{General Aspect of Project Life Cycle}

Project can be viewed by different meaning depends on its system theory/contexts. For instance, [5] define project as "a temporary endeavour undertaken to create a unique product, service or result". The word "temporary" refer to characteristic of the project that has beginning and an end. On the other hand, unique means that project involve doing something that has not been done before. There might be a similar of previous project but there are unique in term of resources, business environment and others [6]. Project life cycle basically consist of four phases; initiation, planning/design, execution, controlling and closing. Each phase in project life cycle is a key factor that would determine successful of the project. Initially, a project started with an "initiation phase" where it involves authorizing a project or phases. Then, it is followed by the "planning phase" as it engages selecting the best alternative in order to achieve the project objective successfully. Next, the "execution phase" is primary focus on coordinating people and other resources for instance equipment and material due to perform well in the project. On the other hand, "monitoring and controlling phase" purpose to ensure the high quality of achievement of project. Lastly, "closing phases" is a formalized process in acceptance of the project[6]. Project management life cycle consist of nine knowledge areas; project integration, project scope, project time, project cost, project quality, project human resource, project communication, project risk, and project procurement management[6].

\section{Design Phase and BIM}

Design is the most significant phase that would influence overall project life cycle. It would establishes the basic program, allocated responsibility, determine activities and resources and all input relating to the project such as personnel skills, technical requirement must be determine at this point . In addition, the evaluation of environment factors, social criteria and procedure must also be included. Moreover, the design phase also involves tasks such as operation plan, work schedule and contingency plan[7]. ICT technology such as CAD and BIM would impact mostly in this phase. Currently, the 2D (CAD) tool use in building design practice become inadequate with the development of construction industries. Compare to the CAD, BIM is more than drawing, BIM consist of vast data due to building design, construction and maintenance information that merge in one proper model. Simply stated drawing produce using BIM is interactive representation model rather than manually coordinated lines which will eliminate coordination error and improve overall quality of the work [5].

BIM is generally a three dimensional digital representation of a building and its build in characteristics[8]. BIM can also be define as "a digital representation of physical and functional characteristics of a facility and a shared knowledge resource for information about facility forming a reliable basis for decision during its life cycle; defined as existing from earliest conception to demolition"[2]. Meanwhile, [10] asserts that BIM can be define as an IT artifact which model the 
physical and functional characteristics of a facility and a shared knowledge resource for information about a facility forming a reliable basis for decisions during its life-cycle; defined as existing from earliest conception to demolition. On the other hand, BIM is focusing on the philosophy for managing and accessing common building and facilities data and information [9]. BIM is applied throughout the facilities life-cycle, from requirements definition through disposal. [9] indicates that the main aim of BIM is to provide installation owners and caretakers with the best information available for making best value decisions and reducing total ownership costs. Implementation of BIM on a project level requires comprehensive planning by facility owners and project participants (designers, contractors, subcontractors, and manufacturers) to ensure successful transition from a traditional approach to incorporate this new technology into the project workflow [10].

\section{Decision Making for Selecting BIM Software}

Research shows that BIM is being broadly adopted across the construction industry with over $50 \%$ of each survey segment - architect, engineers, contractors and owners utilizing the tools at moderate levels or higher [11].[10] also identified that architects are the heaviest users of BIM with $43 \%$ using it on more than $60 \%$ of their projects in 2009 . In addition, the study also reveal that contractors are the lightest users of BIM with nearly half (45\%) using it on less than $15 \%$ of projects and a quarter $(23 \%)$ using it on more than $60 \%$ of projects. At the moment, there are variety of BIM software packages available in the market for AEC inductry. According to [12], BIM software can be grouped under 6 categories such as Architechture, Sustainability, Mechanical, Electrical \& Plumbing (MEP), Construction, and Facility Management.

Prior embarking into BIM project, designers need to select an appropriate software for their construction project. There are various software tools available for selection such as Revit, Tekla and Vico, Navisworks and Solibri Model Chekcer, OPS and BIMServer[4]. It is vital to select appropriate BIM software due to variability of cost and features as it can affect the overall construction project execution throughout building lifecycle. Table 1 presented the list of BIM software and its related AEC domain.

Table 1: List of Software in AEC Industry ([12], [13])

\begin{tabular}{|c|c|}
\hline AEC Domain & Software Name \\
\hline Architecture & $\begin{array}{l}\text { Autodesk Revit Architechture, Graphisoft ArchiCAD, Nemetschek } \\
\text { Allplan Architecture, Gehry Technologies - Digital Project } \\
\text { Designer, Nemetschek Vectorworks Architect, Bentley Architecture, } \\
\text { 4MSA IDEA Architectural Design (IntelliCAD), CADSoft } \\
\text { Envisioneer, Softtech Spirit, RhinoBIM (BETA) }\end{array}$ \\
\hline Sustainability & $\begin{array}{l}\text { Autodesk Ecotech Analysis, Autodesk Green Building Studio, } \\
\text { Graphisoft EcoDesigner, IES Solutions Virtual Environment VE- } \\
\text { Pro, Ebntley Tas Simulator, Bentley Hevacomp, DesignBuilder }\end{array}$ \\
\hline Structures & $\begin{array}{l}\text { Autodesk Revit Structure, Bentley Strutural Modeler, Bentley RAM, } \\
\text { STAAD and ProSteel, Tekla Structures, CypeCAD, Graytec } \\
\text { Advance Design, StrutureSoft Metal Wood Framer, NemetSchek } \\
\text { Scia, 4MSA Strad and Steel, Autodesk Robot Structural Analysis }\end{array}$ \\
\hline MEP & $\begin{array}{l}\text { Autodesk Revit MEP, Bentley Hevacomp Mechanical Designer, } \\
\text { 4MSA FinaHVAC+FineLIFT+FineELEC+FineSANI, Gehry } \\
\text { Techologies - Digital Project MEP Systems Routing, CADMEP } \\
\text { (CADduct/CADmech) }\end{array}$ \\
\hline $\begin{array}{l}\text { Construction (Simulation, Estimating, } \\
\text { and Const. Analysis) }\end{array}$ & $\begin{array}{l}\text { Autodesk Navisworks, Solibri Model checker, Vico Office Suite, } \\
\text { Vela Field BIM, BentleyConstrucSim, Tekla BIMSight, Glue (by } \\
\text { Horizontal Systems), Synchro Professional, Innovaya }\end{array}$ \\
\hline Facility Management & $\begin{array}{l}\text { Bentley Facilities, FM: Systems FM: Interact, Vintocon ArchiFM } \\
\text { (For ArchiCAD), Onuma System, EcoDomus }\end{array}$ \\
\hline
\end{tabular}


Figure 1 illustrates 25 possible uses of BIM throughout building lifecycle [14]. Due to the variability of BIM functional, it is essential to identify the appropriate BIM uses for a target project from Planning to Operating Phase.

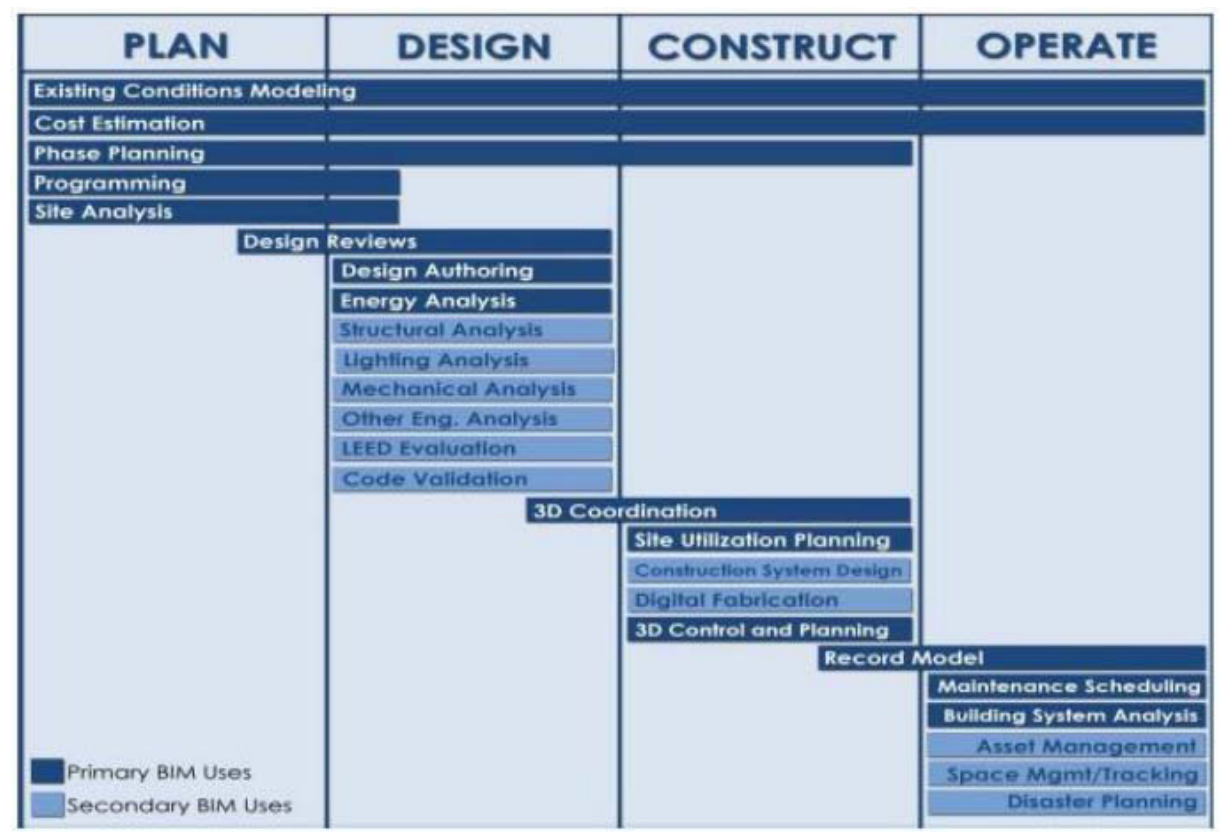

Figure 1: BIM Uses Throughout A Building Lifecycle [13]

In literature, there is limited study attempt to thoroughly investigate the criteria and decision process to select appropriate BIM software. CREAM (2012) indicates that availability, affordability, diffusion, training, and support are among some generic criteria to select BIM software. Hence, there is a need to aid decision making towards BIM software selection to cater the project and client's need. Till date the study to identify the critical criteria and decision support for BIM selection in construction are largely neglected. Only [14] proposed a model for evaluation of BIM software package where the study only uses simple descriptive statistics and does not consider Multi Criteria Decision Making (MCDM) technique. Most the researchers have agreed that MCDM method is an effective decision techniques that involves an evalution and comparison alternative problems [15][21]. In MCDM literature, a substantial work of MCDM as a decision techniques has been performed in the past [16], [21]-[23]. Thus, by considering the aforementioned issues, the main research problem is identified as follows:

"The lack of multi criteria decision support framework to assist BIM software selection for construction project"

Due to unavailability for decision support, it is desirable to a develop a computerised multi-criteria decision support system for BIM software selection.

\section{Discussion and Conclusion}

Nowadays technology is major contributor to construction industry. Introducing to BIM technology has become increasingly important as it advantages will affect the productivity and quality of a project among constructor. Moreover, previous research has proven fact that as well implementation of BIM will increase quality, scheduling, safety, reducing cost and error of the project throughout project life cycle. As the used of BIM become more prevalent, construction companies facing a market full of option in BIM software that available. Due to the variety of BIM tools on the market, the selection of 
the right BIM software for a certain construction project becoming more apparent. However, the needs to aid the decision making often overlooked. In contrast, there are some of these companies tend to make decision making on selection of BIM software base on marketing campaign by the software vendor and popular software package rather than using an appropriate analysis of the company needs[24]. However, the literature is limited to reveal any significant of decision support regarding of BIM software selection. Thus a multi criteria decision support for BIM software selection is vital towards successful construction project throughout building lifecycle.Therefore this research attemp to fill the gap by develop a decision making framework and prototype to solve BIM software selection in an innovative way.

\section{Acknowledgements}

The authors gratefully acknowledge the support by the Ministry of Education Malaysia for providing the funding under Research Acculturation Grant Scheme (RAGS). Many of the parts of this paper were originally written in the process of preparing several grants proposal and parts of student's postgraduate thesis.

\section{References}

1. Gann, "Building innovation - complex constructs in a changing world," pp. 150-186, 2000.

2. B. Succar, "Building information modelling framework: A research and delivery foundation for industry stakeholders," Autom. Constr., vol. 18, no. 3, pp. 357-375, May 2009.

3. V. R. Perumal and A. H. A. Bakar, "communication in construction idustry.pdf," World Appl. Sci. J., 2011.

4. CREAM, "BIM Industrial Transformation in Australia," 2012. [Online]. Available: http://www.cream.com.my. [Accessed: 01-Oct-2012].

5. J. V. Kumar and M. Mukherjee, "Scope of Building Information Modeling ( BIM ) in India," vol. 2, no. 1, pp. 165-169, 2009.

6. A. guide to the project management body of knowledge PMBOK, Project Management Body of Knowledge A Guide to the A Guide to the A Guide to the Project Body of Project Management Knowledge Management Body of Knowledge Knowledge, 2000 Editi. Project Management Institute, 2001.

7. L. J. Goodman, Project planning and management. New York: Van Nostrand Reinhold Company Inc, 1988.

8. M. F. Hergunsel, "Benefit of Building Information Modelling for construction managers and BIM based scheduling," Worcester Polytechnic Institute, 2011.

9. E. W. East, "BIM for Construction Handover," J. Build. Inf. Model., pp. 25-28.

10. M. Reichardt, “Convergence of Standards,” J. Build. Inf. Model., pp. 36-38, 2007.

11. Liu, "Feasibility Analysis of BIM Based Information System for Facility Management at WPI," Worcester Polytechnic Institute, 2010.

12. Jeffrey. A. Pinheiro, "List of BIM Software," 2013. [Online]. Available: http://therevitkid.blogspot.com/2013/06/list-of-bim-software.html. [Accessed: 11-Oct-2013].

13. Broquestas, "List of BIM software \& Providers," 2010. [Online]. Available: http://www.cadaddict.com/2010/03/list-of-bim-software-providers.html. [Accessed: 01-Oct-2012].

14. R. Rohena, "Building Information Modelling ( BIM ) Implementation in Naval Construction," Lousiana State University, 2011.

15. R. F. Saen, "The Use of Artificial Neural Networks for Technology Selection in the Presence of Both Continuous and Categorical Data," vol. 6, no. 9, pp. 1177-1189, 2009.

16. M. Salehi, “Application of Fuzzy TOPSIS Technique for Evaluation of Project," World Appl. Sci. J., vol. 6, no. 6, pp. 776-783, 2009. 
17. D. Sedighizadeh and S. Sedighizadeh, "A Consolidted MADM Method under Uncertainly for Strategic Resource Planning,” World Appl. Sci. J., vol. 13, no. 7, pp. 1661-1667, 2011.

18. S. Sorooshian, A. Anvari, M. Salimi, and E. Falatoonitoosi, "Interrelation Study of Entrepreneur's Capability 1,2," vol. 17, no. 7, pp. 818-820, 2012.

19. M. Gholampour and M. Alvandi, "Order Preference of Efficient Stakeholders on Organization Effectiveness and Their Related Goals via TOPSIS," World Appl. Sci. J., vol. 10, no. 5, pp. 494507, 2010.

20. E. Ataei and A. Branch, "Application of TOPSIS and Fuzzy TOPSIS Methods for Plant Layout Design," vol. 24, no. 7, pp. 908-913, 2013.

21. P. Adhikary, S. Kundu, P. K. Roy, and A. Mazumdar, "Optimum selection of Hydraulic Turbine Manufacturer for SHP : MCDA or MCDM Tools,” World Appl. Sci. J., vol. 28, no. 7, pp. 914919, 2013.

22. B. Kalantari, H. Mehrmanesh, and N. Saeedi, "Ranking the Driving Affecting Factors on Management Accounting : Business Intelligence Approach,” World Appl. Sci. J., vol. 20, no. 8, pp. 1147-1151, 2012.

23. A. R. Moghassem, "Comparison among Two Analytical Methods of Multi-Criteria Decision Making for Appropriate Spinning Condition Selection,” World Appl. Sci. J., vol. 21, no. 5, pp. 784-794, 2013.

24. J. M. Ruiz, "BIM Software evaluation model for general contractors," Universty of Florida, 2009. 